\title{
Entre la cooptación y la resistencia: de la Femvertising a la Publicidad Profem
}

\author{
Between Co-optation and Resistance: \\ From 'Femvertising' to 'Profem Advertising'
}

MARÍA ISABEL MENÉNDEZ MENÉNDEZ (Universidad de Burgos)

Artículo recibido: 5 de septiembre de 2018

Solicitud de revisión: 9 de septiembre de 2018

Artículo aceptado: 8 de enero de 2019

Menéndez Menéndez, María Isabel (2019). Entre la cooptación y la resistencia: de la Femvertising a la Publicidad Profem. Recerca. Revista de Pensament i Análisi, 24(2), pp. 1538 .

\section{Resumen}

La Femvertising ha aparecido con fuerza en los últimos años como una estrategia de comunicación persuasiva que intenta eliminar los estereotipos de género al tiempo que trabaja por el empoderamiento de las consumidoras. Sin embargo, el carácter esencialmente comercial de la publicidad plantea dudas sobre sus verdaderos fines. Si bien deberían tender al cambio social, siempre emerge la sospecha ante la posible instrumentalización del feminismo en función de objetivos comerciales. El presente artículo pretende contribuir a paliar la escasez de bibliografía especializada sobre Femvertising, por lo que comienza por ofrecer antecedentes de este tipo de publicidad, plantea luego los nudos teóricos que deben abordarse desde la filosofía feminista y, finalmente, construye una metodología para analizar o disenar publicidad que genere feminismo (Advertising Profem o Publicidad Profem), enfoque más adecuado para los intereses de género que la definición como publicidad feminista.

Palabras clave: feminismo, publicidad, empoderamiento, género, femvertising.

\section{Abstract}

'Femvertising' has gained relevance in the last few years as a strategy of persuasive communication that tries to eliminate gender stereotypes while promoting the empowerment of female consumers. However, the essentially commercial quality of advertising raises doubts about its actual aims. Although 'femvertising' is supposed to tend towards social change, there is always some suspicion about its instrumentalization of feminism for commercial purposes. This paper tries to fill a gap within the specialized bibliography on 'femvertising'. In order to do so, it revises its origins, it explores its main theoretical keys 
from the point of view of feminist philosophy and, finally, it elaborates a method to analyze or design a type of 'advertising that generates feminism', which we have dubbed 'profem advertising, taking an approach that seems to be more useful for gender-based interests than the more problematic definition of 'feminist advertising'.

Key Words: feminism, advertising, empowerment, gender, femvertising.

\section{INTRODUCCIÓN ${ }^{1}$}

Feminismo y publicidad parecen dos términos antagónicos, dado que la publicidad se construye a partir de la utilización de estereotipos fácilmente comprensibles (Jalakas, 2017), mientras que la crítica feminista sostiene una relación complicada con el discurso publicitario al que históricamente ha definido como sexista por su instrumentalización de la imagen femenina, la recurrencia en la utilización de enfoques machistas o degradantes para las mujeres y la nula voluntad en eliminar la estereotipia de género. En el mismo sentido, las consumidoras suelen referir que las imágenes publicitarias les provocan malestar, especialmente en los aspectos relacionados con la imagen corporal (McArthur y Resko, 1975; Rincón, 1997; Lynn, Hardin y Walsdorf, 2004; Royo-Vela, Küster-Boluda y Vila-López, 2005; Knoll, Eisen y Steinhagen, 2011; Navarro y Martín, 2011; Hernández-Ruiz, Martín y Beléndez, 2012). Con todo, la crítica feminista no es la única que se interesa por el discurso publicitario, cuestionado históricamente por su posición ética (Feenstra, 2013).

En este marco surge un nuevo tipo de publicidad que se ha bautizado como Femvertising. Según algunos textos, como el de Medeiros, Bulhões y Dantas (2015), el concepto nació como tal en el 2014, en la Advertising Week de Nueva York, uno de los eventos publicitarios más importantes del mundo, con la exposición de Samantha Skey, directora de ventas de SheKnows Media. La ejecutiva desveló algunos datos de una encuesta que demostraba que construir imágenes positivas era beneficioso para las marcas. ${ }^{2}$ SheKnows recomendaba romper con prácticas habituales en los mensajes comerciales como el uso excesivo de Photoshop sobre el cuerpo femenino o la representación de los

1 El presente texto es un resultado del proyecto I+D FEM2017-83302-C3-1-PB (2018-2021), «Produsage juvenil en las redes sociales: construcción de la identidad sexual y gestión de las desigualdades de género», financiado por el Ministerio de Industria, Economía y Competitividad del Gobierno de España en el marco del Programa Estatal de Fomento de la Investigación Científica y Técnica de Excelencia, Subprograma Estatal de Generación del Conocimiento en el marco del Plan Estatal de Investigación Científica y Técnica y de Innovación 2013-2016.

2 Una síntesis gráfica del estudio puede consultarse en la web de la empresa: goo.gl/p9HrZS. 
varones como incapaces ante las tareas de cuidado. Estos hallazgos resaltan la necesidad de que los mensajes publicitarios representen con mayor precisión a sus públicos para relacionarse mejor con ellos y optimizar las actitudes de marca (Drake, 2017). ${ }^{3}$

A pesar de este nacimiento poco feminista - SheKnows recomienda usarlo más por razones comerciales que de justicia social-,el neologismo se construye a partir de la suma de Feminism y Advertising (Becker-Herby, 2016), lo que debería traducirse como Publicidad feminista — también se denomina Publicidad Go-girl, Pro-género, Pro-mujer o Ad-her-tising_, y se refiere a una publicidad que, además de evitar mensajes lesivos sobre las mujeres - estereotipos de género, vejación de la imagen femenina, ridiculización de las féminas- se esfuerza por ofrecer un discurso potencialmente emancipador. Es decir, se trata de una publicidad con responsabilidad social que cuestiona los estereotipos de género y promueve el empoderamiento femenino.

$\mathrm{Si}$, como ha destacado la literatura especializada, la publicidad sexista es un freno a la igualdad, la publicidad feminista podría trabajar a su favor. Sin embargo, existe la sospecha de su instrumentalización únicamente con objetivos comerciales. En efecto, algunas posiciones definen cualquier uso de las políticas feministas desde la cultura popular como un feminismo bastardo y apolítico. Sobre fenómenos culturales similares, Angela McRobbie (2009) considera que contribuyen a desarmar el movimiento feminista. Rosalind Gill (2007) opina que son opciones que sugieren que las mujeres tomen el control de sus vidas mediante el consumo y no a través de la lucha colectiva. Desde este punto de vista, la publicidad nunca podrá liderar el cambio social. Este planteamiento no es el único posible. Oliviero Toscani, famoso por sus campañas para la empresa Benetton, defiende que la publicidad no puede ser una comunicación sin utilidad social, de ahí su elección de imágenes dramáticas de la vida real, como la icónica fotografía de un enfermo terminal de sida. Las campañas de Toscani fueron efectivas - aumentaron las ventas en un $20 \%$-, pero también crearon un nuevo paradigma publicitario, en el que comenzaron a utilizarse la ética, la ecología y la solidaridad como argumentos (Sánchez, 2014).

Más allá de la definición de falso feminismo, y de acuerdo con Jalakas (2017), puede ser útil explorar cómo encajan estas campañas en el feminismo actual, especialmente entre las jóvenes, quienes las utilizan y dotan de sentido $\mathrm{Al}$ respecto se puede consultar el reportaje publicado en El País, el 31 de octubre de 2014, disponible en:
goo.gl/rGRcR2. 
en las redes sociales, pero que también forman parte de la publicidad televisiva y digital. La Femvertising podría contribuir a cierto despertar feminista entre la juventud, favoreciendo el debate sobre las cuestiones de género. Entre las audiencias, muy poco analizadas de momento, parece que estos mensajes despiertan interés. Según el citado estudio de SheKnows, algunas de estas campañas han logrado hacerse muy populares: la famosa \#Like a Girl de la firma Always ha sido visualizada más de 61 millones de veces y el anuncio más compartido en YouTube en el 2013 fue uno de la campaña Real Beauty Sketches de Dove. En España, Deliciosa Calma de Campofrío superó los 13 millones de visualizaciones en solo tres meses y se convirtió en el vídeo más popular en YouTube del año 2016.

Un trabajo reciente de Abitbol y Sternadori (2016) sobre la percepción de la Femvertising reveló que la mayoría de las personas habían dicho sentirse bien con los mensajes de la publicidad expuesta, aunque no necesariamente mostraban su apoyo al producto o la firma. Reportaban que algunos mensajes les habían hecho pensar, por primera vez, en cuestiones de género. Algunas personas sugirieron que las estrategias no eran sinceras, que eran poco más que una pantalla que las marcas usaban para incrementar sus ganancias y también se advirtió de la posibilidad de instrumentalizar el feminismo desde una cultura que promovía la idea de que cualquiera puede ser feminista, aunque el sentirse feminista se limitara al consumismo, conceptualizándolo como algo amable, fabuloso, chic. Estas opiniones revelaban la sospecha del interés espurio de las marcas por su utilización como una estrategia de ventas, sin voluntad real de cambio social e incluso como una simple táctica de corrección política. Finalmente, muchos varones pensaban que esta publicidad era negativa para ellos, para quienes no se proponían mensajes de empoderamiento.

Quizá la característica más relevante de este estudio es que parecía que la Femvertising solo era eficaz si reflejaba honestamente la cultura interna de una empresa (Abitbol y Sternadori, 2016). La publicidad, como herramienta de comunicación del sistema comercial, estará siempre bajo sospecha sobre sus verdaderos intereses. Así, ya existen recelos sobre el verdadero interés de las campañas que promueven la protección del medio ambiente o la lucha contra el cáncer de mama entre otras. Estas iniciativas han sido problematizadas desde conceptos como Greenwashing o Pinkwashing respectivamente, poniendo en cuestión el compromiso real con el cambio social en maniobras publicitarias que serían poco más que un lavado de cara que encubre el objetivo comercial. En definitiva, se pone bajo la lupa la responsabilidad social corporativa (RSC) 
al tiempo que se exige que exista algo más que un comercial desde el que se visibilice una problemática.

El presente artículo adopta la fórmula de ensayo teórico, con el objetivo de ofrecer una reflexión crítica sobre un paradigma, la Femvertising, que presenta interesantes retos en el actual marco neoliberal. La publicidad se define ahora como feminista por lo que, parafraseando a Celia Amorós, la filosofía debe instalarse en la hermenéutica de la sospecha: ¿puede la publicidad ser feminista siendo, como es, un instrumento clave del mercado? Si puede serlo, ¿cómo diferenciarla de aquella que no lo es, pero lo parece? Para intentar deshacer este nudo, el texto ofrece, en primer lugar, hechos que podrían considerarse orígenes o antecedentes de la Femvertising para detenerse luego en las cuestiones teóricas, desde las que analizar su ambivalencia y los intereses de género que compromete. La hipótesis que se propone es que, dado el carácter comercial intrínseco a la publicidad, la definición de esta como discurso feminista siempre quedará bajo la sospecha de fines espurios, lo que sitúa el debate en una encrucijada sin solución. De ahí que el artículo proponga en su apartado final una cartografía de lo que debería ser, no una publicidad feminista -dado que no es viable su definición como tal- sino un enfoque capaz de generar feminismo desde la publicidad (Advertising Profem), esto es, capaz de despertar en el público la reflexión y la acción sobre las cuestiones feministas. Esta cartografía puede ser útil como metodología para analizar productos publicitarios en investigaciones posteriores y también puede servir como mapa para profesionales de la publicidad con interés en diseñar campañas que generen feminismo.

\section{1. ¿ES NUEVA LA FEMVERTISING? UN VIAJE HACIA SUS ORÍGENES}

El concepto Femvertising es reciente, no así las herramientas y los recursos en los que se apoya. La publicidad moderna comenzó a interesarse por las mujeres como público objetivo desde muy pronto y no solo porque, como indican los estudios de mercado, son las mujeres las que toman la mayoría de las decisiones de compra. Ellas responden a un perfil pluriconsumidor: «son compradoras de objetos para el consumo personal, para el hogar, para los niños y, en ocasiones, para el hombre» (Carosio, 2008: 152). Sin embargo, para hablar de iniciativas similares a la Femvertising, las campañas deben no solamente dirigirse a mujeres como target, sino incorporar ideas de empoderamiento y eliminación de estereotipos de género. 
Para algunos autores, las estrategias comerciales dirigidas específicamente a mujeres comenzaron en los años veinte del siglo XX, con el desfile de las Antorchas de la Libertad (Abitbol y Sternadori, 2016). El 31 de marzo de 1929, en Nueva York, grupos de mujeres comienzan a fumar en público. Fumar, un acto social construido con sus propias etiquetas y códigos, en las mujeres «estaba asociado a la decadencia moral y la promiscuidad sexual, identificándose con artistas, prostitutas o lesbianas; y, en general, con mujeres que exhibían una feminidad desviada» (Jiménez, 2012: 88). Diez mujeres cuidadosamente elegidas aparecieron fumando en la Quinta Avenida (Gladwell, 1998) mientras la famosa feminista Ruth Hale arengaba: «iMujeres! Encended otra antorcha de la libertad. Luchad contra otro tabú de género» (Brandt, 2007: 84). Todo formaba parte de una campaña que George Washington Hill, presidente de la American Tobacco Company, había encargado a Edward Bernays para aumentar el consumo de tabaco entre las mujeres. Bernays incorporaba las teorías psicológicas que había aprendido de su tío, el psicoanalista Sigmund Freud, relacionando la forma cilíndrica del cigarrillo con la fijación oral femenina: si los pitillos equiparaban a la mujer con el hombre, entonces serían como sus antorchas de la libertad, sería suficiente con relacionar el tabaco con un reto al machismo (Bernabé, 2018). Algunas reclamaciones feministas eran ya un hecho, como la lucha por el sufragio. Así, la campaña diseñada por Bernays podría ser el embrión de la Femvertising.

Otro periodo que nos ofrece cierto diálogo entre el feminismo y la publicidad lo encontramos décadas más tarde. Los años ochenta y noventa asistieron a una reacción conservadora, tras la explosión del feminismo sesentayochista, reacción en la que jugarían un papel relevante los medios de comunicación, tal y como se analiza en el ya mítico texto de Susan Faludi (1991). Entonces ya se había publicado otra obra crítica con la situación de las mujeres, en la que se destacaba el rol de la prensa y la publicidad en la identidad corporal (Wolf, 1990). El libro de Wolf sería el más influyente de un pensamiento que había comenzado con Susie Orbach y su libro Fat is a Feminist Issue (1978), desde el que denunciaba la opresión estética. También el activismo se preocupaba por el discurso de la belleza. Desde hacía tiempo, mujeres de Los Ángeles habían conformado un grupo denominado The Underground Fat. Problematizaban la gordura, organizaban protestas contra la gordofobia, promovían grupos de apoyo y llevaban sus mensajes a medios de comunicación y representantes de la política. Este tipo de activismo se desarrollaría en muchos otros lugares, a ambos lados del Atlántico y en la academia anglosajona culminaría con la creación de los Fat Studies. 
Son algunos ejemplos de un movimiento tanto activista como intelectual que denunciaba el malestar de las mujeres, muy relacionado con las industrias culturales y el cada vez más exigente canon corporal, y cuyo altavoz más evidente era la publicidad. En este contexto aparece la primera campaña que hoy podríamos definir como Femvertising. The Body Shop lanzaba en 1997 Love Your Body, protagonizada por la muñeca Ruby - fuera del estándar de delgadez, inspirada más bien en la belleza pictórica de Rubens- con eslóganes como «Hay 3000 millones de mujeres en el mundo y solo 8 son "supermodelos"». Ruby desafiaba los estereotipos y pretendía poner freno a la influencia de la industria cosmética en la insatisfacción que sentían la mayoría de las mujeres. Su desafío abrió el debate sobre autoestima e imagen. The Body Shop fue demandada en Estados Unidos por Mattel, la empresa que fabrica las muñecas Barbie, porque consideraron que perjudicaba las ventas de su producto. Lo cierto es que Ruby era la imagen anti-Barbie y discutía la irrealidad de la muñeca más famosa. Desde The Body Shop, la activista social Anita Roddick fue una de las primeras que supo combinar ética y negocio desde el punto de vista de género. A esta campaña le siguieron otras antes de que vendiera la firma.

Con todo, es común identificar el origen de la Femvertising ya en el siglo XXI, en la campaña del 2004 de la firma Dove, creada en 1955 y perteneciente a la multinacional Unilever. Fue bautizada como Real Beauty (Medeiros, Bulhões y Dantas, 2015; Becker-Herby, 2016; Jalakas, 2017) y era el resultado de un análisis de mercado asesorado por Susie Orbach y Nancy Etcoff, estudio que reveló que las mujeres consideraban que el concepto de belleza se había vuelto inalcanzable, lo que afectaba a su autoestima.

Tanto The Body Shop como Dove colocan la estrategia de publicidad en el marco de los productos relacionados con la estética, una de las cuestiones más ambivalentes de la Femvertising porque, apoyándose en la construcción teórica del feminismo que identificó el discurso de la belleza con la opresión, promueve que más mujeres se sitúen en el canon, pero no tanto propone la desaparición de este. Es decir, se ensancha el espacio en el que las mujeres pueden encajar, pero sigue siendo un lugar incómodo tanto para las que caben dentro como para las que quedan fuera. Esta crítica es de difícil respuesta desde la Femvertising pues, aunque algunas firmas están desarrollando campañas para otro tipo de productos, la mayoría lo hacen en el contexto del culto al cuerpo.

El éxito de la Femvertising también está relacionado con la gran visibilidad que ha logrado el feminismo en el último lustro. La publicidad se aprovecha 
del impulso recibido por parte de las celebridades de la cultura popular: actrices, creadoras, cantantes. Desde el 2014 hemos asistido a la popularización de un término antes denostado. Aunque pueden argumentarse críticas al feminismo que promueven las mujeres de la industria - muy alejadas de las mujeres reales y sus necesidades-, lo cierto es que actrices como Emma Watson, Jennifer Lawrence o Lena Dunham han enarbolado públicamente su causa mientras que la estrella del pop Beyoncé pasaría a la historia al diseñar un escenario con la palabra en letras gigantes y citas de una charla de la novelista nigeriana Chimamanda Ngozi, famosa por su texto We Should All Be Feminists (Fernández, 2017). Las galas de entrega de premios prestigiosos se empapan de discursos feministas por parte de unas celebridades que hasta hace muy poco no osaban ponerse la etiqueta. La marcha de las mujeres del 2017 y el éxito del \#MeToo, que cruzó continentes, mostró que «aquello no iba solo con las adolescentes o con las actrices famosas» (Valdés, 2018: 144). La principal novedad no es su existencia —el feminismo no es una moda sino un pensamiento filosófico y político con siglos de historia-, sino su capacidad para llegar a la agenda de los medios de comunicación y, junto con la viralidad conseguida en las redes sociales, convertirse en un discurso capaz de movilizar a mujeres en las calles de todo el mundo.

El feminismo, amplificado de manera inusual por las redes sociales, ha irrumpido en la agenda mediática. Cierto es que se trata únicamente de un feminismo de mujeres privilegiadas, lo que Fraser $(2015,2018)$ denomina feminismo corporativo frente al feminismo del $99 \%$ y que otras autoras califican como neoliberal, esto es, un feminismo con límites de clase e intereses comerciales, que no cuestiona las estructuras jerárquicas, sino que pelea por ascender en ellas y que abandonaría las ideas radicales de igualdad y justicia social. Con todo, hoy parece inevitable que el término forme parte de cualquier discurso mediático, también del publicitario. Si las mujeres se declaran feministas y el feminismo ha irrumpido en espacios como la moda o la cultura audiovisual, la publicidad no podía quedarse atrás.

\section{2. ¿PUEDE LA PUBLICIDAD SER FEMINISTA? NUDOS TEÓRICOS}

La investigación académica sobre Femvertising es todavía escasa y, en lengua española, prácticamente inexistente. Aunque el concepto como tal sea contemporáneo, puede considerarse una evolución del Commodity Feminism que representa la tendencia en publicidad que intenta aunar activismo y femi- 
nismo a través del consumo. Al calificar sus productos como una opción feminista, se construye una marca que permite a su público respaldar la causa, de manera que se propone un consumo apoyado en la identidad del producto y no el producto mismo (Marcus, 2016).

El Commodity Feminism suele ser considerado como una apropiación del feminismo con fines comerciales, estrategia criticada por reducir la política feminista a un artículo mercantilizado y destinado al público de masas (Gill, 2008a). Las marcas intentan canalizar el mensaje feminista a través de marcadores semióticos que se pueden adjuntar a nombres de productos, traduciendo las reclamaciones de las mujeres en signos comerciales. Aunque a primera vista esto puede aparecer como evidencia de pluralismo, se trata de un proceso inherentemente contradictorio: una dialéctica continua entre el discurso dominante y el de resistencia (Goldman, Heath y Smith, 1991). Para multitud de autoras, este feminismo mercantil se apropia estratégicamente de los valores feministas, poniendo su potencial político al servicio de las marcas (Lazar, 2006; Gill, 2008b; Marcus, 2016) mediante una estrategia corporativa centrada en el consumo como fuente de identidad.

En este contexto, se hace imprescindible introducir la variable neoliberalismo, modelo que propone una sociedad basada en un mercado radicalmente libre a través de estrategias como la desregularización o la privatización ( $\mathrm{Su}$ garman, 2015). Para lo que interesa al presente artículo, el neoliberalismo ha enfatizado la idea de la elección y la libertad individuales como formas de poder, desviando lo social hacia lo personal: los individuos se gobiernan a sí mismos en el marco de la libertad de acción, internalizando la competencia como modo de vida y la emprenduría de uno mismo (Read, 2009). Esta idea del beneficio individual de cada acción va a chocar frontalmente con las propuestas del feminismo que siempre han partido de la lucha colectiva. Pero también remite a la ginofobia diagnosticada por Valcárcel (2000): las mujeres son los sujetos peor parados de un sistema de mercado teóricamente neutro. El neoliberalismo ha legitimado el enfoque comercial de cualquier cuestión, incluyendo cuerpos, fertilidad y sexualidad de las mujeres que pueden formar parte del intercambio monetario, constituyéndose en formas de construcción individual que permiten el éxito social (Menéndez, 2015).

Es aquí donde el paradigma posfeminista ha construido un discurso que problematiza e incluso destruye la propia agenda feminista en el nuevo siglo. El concepto de posfeminismo ha sido delimitado por pensadoras como Projansky (2001), Ferriss y Young (2008), McRobbie (2009) o Munford y Waters (2013), quienes consideran que, incluso aceptando la gran heterogeneidad de 
las posiciones, se trata de una visión que sugiere que las mujeres ya han alcanzado todo lo necesario para su emancipación y libertad. Este posfeminismo, divulgado a través de los medios de comunicación de masas, constituye una nueva forma de antifeminismo. Mediante la cultura consumista y su relación con el orden capitalista, fomenta narrativas en las que la feminidad se celebra a partir de la obtención de bienes materiales. Son muchas las autoras que sostienen que el posfeminismo es una nueva forma de backlash en el sentido dado por Faludi (1991). En consecuencia, el feminismo necesita estar atento ya que el neoliberalismo nunca ha tenido interés en las libertades de las mujeres, desde el momento en que ha explotado su trabajo reproductivo.

El posfeminismo parte de una defensa radical del individualismo. El proceso de autoconciencia de las mujeres, el sentimiento de colectividad y las luchas comunes que caracterizaron al feminismo de segunda ola iban a desaparecer para ser sustituidos por un individualismo feroz (Fraser, 1997). El llamamiento nada disimulado a la desarticulación del movimiento feminista no tuvo otra consecuencia que la despolitización de las mujeres como clase para la imposición en su lugar de la ética de la elección personal. Desaparece un principio básico del feminismo, el sentimiento de compartir la misma opresión, y nace el reto de «hacer que el feminismo represente algo más que una clase de mujeres blancas privilegiadas» (Rowe, 2005: 45). En este sentido, la interseccionalidad entre las diferentes variables de opresión también se revela como una cuestión esencial del análisis, mientras que la resistencia a pensarse colectivamente constituye, de acuerdo con McRobbie (2007), una pérdida enorme en una época en la que las acciones colectivas siguen siendo necesarias (Menéndez, 2017).

El término clave que permite avanzar entre estos nudos teóricos será el de empoderamiento. Se trata de un concepto sociopolítico, capaz de trascender la participación política formal, que en los setenta comienza a aplicarse en los movimientos de mujeres como respuesta a la necesidad de generar cambios en las relaciones de poder entre sexos (De León, 1997). El empoderamiento está relacionado, según Friedmann (1992), con tres tipos de poder: 1) social o acceso a la riqueza productiva; 2) político o acceso a la toma de decisiones; y 3 ) psicológico o capacidad individual. Rowlands (1997) menciona tres dimensiones: 1) personal o desarrollo del yo, la confianza y la capacidad individual; 2) relaciones próximas o capacidad de negociar en las interacciones y decisiones; y 3) colectiva o participación en las estructuras políticas y en las acciones basadas en la cooperación colectiva. El empoderamiento, por tanto, se desarrolla en dos planos: el individual, proceso por el cual las personas incrementan sus 
niveles de autoestima y capacidad a partir de la identificación de sus propias necesidades, y el colectivo, que implica la unión de los individuos para luchar por objetivos comunes.

Para Porroche-Escudero (2017: 59), «el desarrollo de la conciencia política es un prerrequisito y una solución para el empoderamiento». Esta autora considera que el empoderamiento debe cumplir cuatro principios para ser considerado como tal: 1) potenciar la capacidad crítica para tomar decisiones autónomamente; 2) reconocer que el empoderamiento no puede ser un monólogo desde el que un discurso experto alecciona al público; 3) transmitir información valiosa y efectiva; y 4) favorecer la conciencia política, impulsando no solo el empoderamiento individual sino también el colectivo, es decir, capaz de generar cambios sociales más allá de la modificación individual.

En la línea que se viene exponiendo sobre la (re)apropiación y despolitización de conceptos subversivos por parte del statu quo, Bacqué y Biewener (2016) destacan que, a partir de los años ochenta, el concepto es adoptado por la derecha norteamericana para ponerlo al servicio de las políticas neoliberales. Tener un empleo y formar parte de la economía de mercado se convierte en el paradigma de individuo gestor de su propia vida; la capacidad de hacer elecciones se reduce a poco más que encontrar un lugar en el consumo. Desaparece la idea de comunidad y únicamente queda la de individualismo en una cadena de equivalencias que articula la «libre elección, competencia, propiedad, trabajo, responsabilidad y self-help» (Bacqué y Biewener, 2016: 95).

La bibliografía suele advertir de su carácter espurio: se trataría de un mensaje que anima a consumir mientras propone roles y valores nada progresistas encubiertos tras fantasías feministas (Douglas, 2010). Para Douglas, el feminismo que resulta de estas estrategias ya no tiene que ver con la emancipación femenina sino con la creación de sujetos consumidores. El resultado, explica Fernández (2017), sería el abandono del mensaje subversivo para encontrar espacio en el mismo sistema, que deja de ser cuestionado. El feminismo es utilizado de forma selectiva e interesada: mientras que las teóricas y académicas siguen siendo casi invisibles, las celebridades ubican la palabra feminista en primera línea sin abandonar su lugar en la cultura de masas desde donde proyectan la feminidad ideal. Roxane Gay (2018) lo llama Thinspiration, recordatorio constante de la distancia que existe entre sus cuerpos y los de la audiencia. Se estaría modificando el rol consumidor, pero a costa de la instrumentalización del activismo y la ideología feminista. Marcus (2016) considera que la idea clave pasa por inculcar en el público la creencia de estar 
realizando cambios significativos, rechazando el destructivo clima sexista anterior.

Es difícil, sin embargo, no observar estas opciones de compra feministas como algo más que una forma de terapia ante la discriminación sistemática de género. Dowsett (2014) sugiere que sería un fenómeno que anima a las mujeres a expresar su empoderamiento mediante el consumo. Se trata de una política tanto liberal como conservadora: liberal en la medida en que ofrece una respuesta a la tensión feminismo/feminidad mediante el apoyo a las políticas de independencia y autodeterminación, pero conservadora en el sentido de considerar a las masas como un problema que necesita control. Además de revalorizar los productos feminizados y las mujeres que los utilizan, transforma las mercancías en una forma de control social. Como se ha expuesto, muchas propuestas de Femvertising agrandan el hueco que las mujeres ocupan, pero no cuestionan el espacio en sí mismo: la afirmación de que todas las mujeres pueden ser bellas amplía el canon, pero no lo destruye. Ninguna afirmación publicitaria se atrevería a proponer que está bien ser fea. Se trata de aceptar la belleza, aunque sea diversa, pero nunca la fealdad.

Dicho de otra manera, las reclamaciones feministas se desactivan y las mujeres se convierten en inofensivas para el sistema, aunque lo hacen a través de un consumo de productos feminizados y mediante la exaltación de la feminidad, la construcción de subjetividades feministas que cada vez más son globales (Dowsett, 2014), otra cosa es que sean realmente emancipadoras. Si bien «en ciertos casos los progresos en la eliminación de estereotipos son notables, en otros se intenta manipular a la audiencia por medio de tácticas contrarias al activismo feminista» (Rodríguez y Gutiérrez, 2017: 337).

De lo anterior se deduce que la Femvertising, más que dar voz a las mujeres, parece una estrategia capaz de rentabilizar la frustración que produce el mandato de feminidad, ofreciendo el consumo como solución. Debemos preguntarnos, escribe Zeisler (2014), si realmente las personas que han comprado productos de estas firmas serán capaces de unirse al verdadero feminismo, ese cuya idea de igualdad no es fácil de vender. Su peligro es convertir el discurso feminista en algo atractivo pero despolitizado, alejado de la incomodidad que siempre han despertado las reivindicaciones feministas. El individualismo que caracteriza el mundo neoliberal, ahora pensado como herramienta para consumir, sustituye las características esenciales del feminismo: su carácter político y colectivo. 


\section{HACIA UNA CARTOGRAFÍA DE PUBLICIDAD GENERADORA DE FEMINISMO}

Como se ha expuesto hasta aquí, la Femvertising es utilizada cada vez más por corporaciones conscientes de la necesidad de crear contextos de responsabilidad social corporativa (RSC). También es un hecho que hoy asistimos a un movimiento feminista más visible y articulado que la década anterior. En este sentido, las acciones en favor de la igualdad pueden ser capaces de intervenir en el aumento de las ventas. No obstante, desde una perspectiva feminista, presenta tensiones por la posibilidad de destruir el lesivo sexismo de la publicidad mainstream a costa de la instrumentalización del propio feminismo, que puede ser domesticado o bien utilizado con fines espurios.

No puede darse, al menos de momento, una respuesta contundente a la pregunta retórica sobre si es posible que exista una publicidad feminista. La publicidad siempre es una herramienta de comunicación, de carácter persuasivo, destinada a aumentar las ventas o el prestigio de la marca, por lo que no podemos exigirle que opere en otro paradigma, más allá de respetar la legislación a la que está sometida. El concepto mismo, Femvertising, es complejo pues la sola existencia de una publicidad feminista de alguna manera está normalizando la existencia de otra que no lo es, dando la oportunidad a las firmas de elegir entre ambas, en lugar de trabajar por la existencia del feminismo como principio de justicia social que recorra todos los mensajes publicitarios.

En este sentido, se podría argumentar que, en lugar de una categoría llamada publicidad feminista o Femvertising —en la línea de publicidad verde o vegana-, se construya más bien una estrategia para realizar publicidad socialmente responsable: no hablaríamos entonces de elaborar una publicidad feminista sino de generar feminismo desde la publicidad, idea esta última que parece más adecuada para los intereses de género. Es decir, construir mensajes publicitarios capaces de incitar al público a la reflexión y la acción feministas. Lo llamaremos Advertising Profem o Publicidad Profem.

A partir de lo anterior, en este epígrafe se sugiere dar un paso más allá y, aceptando la ambivalencia del discurso y la posibilidad de que las marcas utilicen este instrumento únicamente con fines comerciales y no de cambio social, establecer algunas ideas que permitan identificar las buenas prácticas para una publicidad que genere feminismo (Advertising Profem) ya que, como ya se ha señalado, no siempre las propuestas son capaces de realizar un mensaje de empoderamiento sin estereotipos de género. 
En primer lugar, el mensaje publicitario debe incorporar la representación de las mujeres desde un punto de vista de igualdad y empoderamiento, entendiendo este como la capacidad de adquirir poder e independencia. Por tanto, ha de ser una estrategia de comunicación que trabaje para potenciar la participación social de las mujeres, que elabore mensajes libres de sexismo y que discuta, elimine o subvierta los estereotipos de género. Por otra parte, debe ser una estrategia publicitaria en sintonía con la empresarial de la firma: la igualdad no puede ser únicamente el eslogan elegido para un anuncio, sino que debe trabajar para conseguirla en su propia organización y en sus relaciones con la sociedad. Como horizonte, esta publicidad debe buscar el cambio social, trabajar por una sociedad más justa que ofrezca una auténtica igualdad de oportunidades y derechos a hombres y mujeres. Para descubrir si este posicionamiento existe en una campaña, o para diseñar publicidad que genere feminismo, es necesario que responda a algunos principios que se explican a continuación (véase la figura 1).

Becker-Herby (2016) propone cinco variables que permiten identificar la estrategia de la Femvertising. Desde aquí proponemos una explicación de dichas variables como instrumentos de análisis o diseño de campañas capaces de generar feminismo: 1) Utilización de la diversidad: al igual que el feminismo contemporáneo es interseccional, en esta publicidad las mujeres deben ser diversas (edad, tamaño, origen étnico) y, por ello, se debe abandonar el cuerpo normativizado de las modelos, romper con la juventud como única representación e incorporar cuerpos no canónicos; 2) Elaboración de mensajes expresamente a favor de las mujeres: deben ser inspiradores e inclusivos, que refuercen lo positivo, buscando sentimientos de confianza y autoafirmación. Deben rechazarse mensajes en los que el producto es la solución a los problemas que tiene la consumidora y proponer una relación de confianza orientada al aumento del bienestar y la felicidad; 3) Ruptura de los estereotipos o mandatos de género: desafío frente a lo que el patriarcado considera que las mujeres o las niñas deben ser. Utilizar escenarios que rompan con los estereotipos: no promover únicamente el espacio doméstico o las tareas típicamente femeninas. Por el contrario, situar a las mujeres en ambientes competitivos, de ocio, atléticos, profesionales o bien neutros. Hay que esforzarse por romper con algunas representaciones todavía monolíticas, como las mujeres cuidadoras o los varones profesionales; 4 ) Minimización de la sexualidad: se trata de negar la mirada masculina (Mulvey, 1975; Berger, 1972) habitual del sexismo publicitario, que construye una mujer para ser mirada por el varón heterosexual desde un paradigma fetichista. Si se exhibe el cuerpo, se debe hacer sin 
emplear poses sexuales o sofisticaciones estéticas. Se buscarán imágenes de mujeres en todo tipo de situaciones, sin ofrecer cuerpos en posiciones imposibles o ridículas; y 5) Representación auténtica de las mujeres: el mensaje de la campaña debe sentirse real. Las consumidoras esperan que la marca sea consecuente más allá de la creatividad, esto es, que realmente esté comprometida con la igualdad de género.

Dicho lo anterior, hay que tener en cuenta que la propuesta de BeckerHerby se acerca con efectividad al objeto de análisis, pero sus resultados pueden ser únicamente formales. Ello quiere decir que se puede realizar una campaña no sexista, que responda positivamente a las variables descritas, pero que no incorpore la idea de empoderamiento. Para afinar los resultados, es necesario añadir un esfuerzo analítico adicional para estudiar si la publicidad, además de estar a favor de la igualdad, es capaz de promover el empoderamiento de las consumidoras. En consecuencia, sugerimos ampliar los indicadores con otros cuatro, elaborados a partir de la propuesta de Porroche-Escudero (2017) ya mencionada.

Figura 1

Generar feminismo desde la publicidad (Advertising Profem)

\begin{tabular}{|c|c|}
\hline \multicolumn{2}{|c|}{ Variables de la Advertising Profem } \\
\hline 1. Utilización de la diversidad & $\begin{array}{l}\text { 6. Fomento de la capacidad crítica para tomar } \\
\text { decisiones }\end{array}$ \\
\hline $\begin{array}{l}\text { 2. Elaboración de mensajes expresamente } \\
\text { a favor de las mujeres }\end{array}$ & $\begin{array}{l}\text { 7. Propuesta de un discurso propio frente al } \\
\text { de una voz experta y exógena }\end{array}$ \\
\hline $\begin{array}{l}\text { 3. Ruptura de los estereotipos o manda- } \\
\text { tos de género }\end{array}$ & $\begin{array}{l}\text { 8. Información valiosa, relevante y efectiva } \\
\text { 9. Impulso de la conciencia política indivi- }\end{array}$ \\
\hline 4. Minimización de la sexualidad & dual y colectiva \\
\hline $\begin{array}{l}\text { 5. Representación auténtica de las muje- } \\
\text { res }\end{array}$ & \\
\hline
\end{tabular}

Fuente: elaboración propia a partir de Becker-Herby (2016) y Porroche-Escudero (2017)

Estos indicadores serán: 6) Fomento de la capacidad crítica: el comercial debe ser capaz de ofrecer un marco de interpretación que demuestre que alguien ha llevado adelante su propia toma de conciencia y, una vez realizado el esfuerzo, ha tomado decisiones por sí misma; 7) Propuesta de un discurso pro- 
pio frente al de una voz experta y exógena: la voz prescriptora en publicidad es un elemento recurrente, la mayoría de las veces masculina y casi siempre - sobre todo en productos de cosmética- con cierto tono autoritario. Las mujeres deben ser quienes construyen el mensaje, sin injerencias; 8) Información valiosa, relevante y efectiva: la publicidad contemporánea cada vez es más emocional y prácticamente ha abandonado los recursos racionales. Sin embargo, dado que el mensaje persuasivo se construye a partir de elementos aspiracionales, también es importante manejar datos que puedan ser percibidos por las consumidoras como interesantes o reales. Es hora de ir abandonando los eufemismos o la invención de palabras imposibles para describir los beneficios de un producto; y 9) Impulso de la conciencia política, no solo individual sino colectiva: la creación de un nosotras, del saber común y de los esfuerzos colectivos es un elemento imprescindible si se desea realizar un mensaje que genere feminismo. Seguir apelando al individualismo, tal y como hacen todos los discursos neoliberales, aleja el mensaje publicitario de este objetivo.

\section{CONCLUSIONES}

La tensión entre cooptación y resistencia, entre empoderamiento y apropiación, entre subversión y domesticación es clave para seguir profundizando en esta publicidad que se denomina a sí misma feminista y que se revela como un espacio de investigación muy fértil que, de momento, carece de bibliografía en lengua española y cuyo acervo en inglés también es escaso. Hay que tener en cuenta tanto su origen - estrategias comerciales diseñadas por firmas que buscan optimizar sus balances comerciales - como su historia, pues ya sabemos que las marcas nunca han dudado en instrumentalizar hallazgos sociológicos o psicológicos para incrementar sus ventas. La publicidad siempre tiene un objetivo persuasivo, comercial o de mejora de la imagen de marca. Exigir una publicidad con una pretensión distinta no tiene sentido. Pretender una publicidad más respetuosa con el público consumidor, sí.

$\mathrm{Si}$ aceptamos que las mujeres son público objetivo de las empresas, es inevitable que estas acomoden sus mensajes a lo que ellas reclaman. Es un hecho, no obstante, que han tardado mucho en escuchar las demandas de muchas mujeres, activistas, académicas y consumidoras, que han confirmado que la publicidad tradicional estaba recorrida por el sexismo y hasta la misoginia. Pero hoy, cuando el feminismo está viviendo una época inédita de visibilización y aceptación social, las propuestas de empoderamiento de las mujeres 
aparecen como una oportunidad, más allá de que las marcas deseen realmente trabajar por el cambio social.

Es posible que unas lo hagan convencidas y otras no, será difícil saberlo en todas las ocasiones, aunque la imagen de las empresas cada vez está más comprometida: las redes sociales son capaces de destruir una campaña en horas, cuando detectan alguna incongruencia. Las firmas deben tomar nota y elegir mensajes feministas solo si realmente creen que son positivos para ellas, para su mercado y para el bien común. Y, preferiblemente, deben hacerlo conociendo qué es una reclamación de los derechos de las mujeres y qué no. Asimismo, deben incluir esta posibilidad en la estrategia global de la marca y revisar su propio posicionamiento como empresa, su política de recursos humanos o cualquier otro elemento que tenga que ver con su relación con las mujeres, dentro y fuera del contexto laboral y empresarial. Cada vez es más fácil acceder a la información de las firmas y, con ello, descubrir mensajes que colisionan ideológicamente con otros. No es suficiente con definirse como feminista, hay que demostrarlo con acciones consecuentes con esta posición filosófica y política que reclama igualdad.

La Femvertising presenta retos a la reflexión feminista. Más allá de las posiciones que proponen que el feminismo debe ser necesariamente anticapitalista - por lo que no cabe paradigma alguno de publicidad feminista-, es un hecho que la industria y el comercio históricamente han trabajado para crear símbolos sociales a través del consumo, por lo que hay que pensar que la utilización de las cuestiones de género siempre tendrá un trasfondo de interés comercial, quedando bajo sospecha la búsqueda del cambio social. Se usan argumentos feministas para vender productos, aunque no debemos olvidar que el propio feminismo no puede comprarse o venderse. Quizá es mejor usar argumentos feministas que perpetuar los estereotipos de género, pero solo si la estrategia es global, la firma convencerá a sus consumidoras. En este sentido, la cuestión ya expuesta sobre la utilización de perspectivas feministas para la venta de productos de belleza, adelgazamiento o moda plantea que no se está interviniendo realmente en los problemas que afectan a las mujeres, sino que se está intentando aliviar el malestar dentro del propio sistema.

Una auténtica posición feminista sería la que adopten aquellas marcas que revisen su modelo de negocio, donde las mujeres pueden no ser bellas ni desear serlo, donde no se perpetúen ideas más o menos tradicionales sobre roles de género, donde se trabaje activamente y en todos los planos por eliminar las numerosas brechas de género que afectan a las mujeres. En consecuencia, hablar de publicidad feminista puede ser una trampa, un gueto conceptual para 
hacer una publicidad como opción frente a otra que con mucha probabilidad seguirá siendo sexista. La etiqueta es problemática en sí misma, de ahí que estas líneas propongan pensar sobre una publicidad que genere feminismo (Advertising Profem) en lugar de hacerlo sobre una publicidad feminista.

Los fenómenos complejos solo pueden recibir respuestas complejas, sin posibilidad alguna de establecer una lectura concluyente, ya sea en este caso si la Femvertising pervierte el propio feminismo o empodera a las consumidoras. Esto es algo habitual en las ciencias sociales y la investigación debe asumir las limitaciones. Sin embargo, lo que es indudable es que las mujeres sienten hartazgo de los modelos, tanto corporales como actitudinales, que propone la publicidad convencional y las marcas deben comprenderlo si desean mantener o mejorar su relación con ellas.

\section{BIBLIOGRAFÍA}

Abitbol, Alan y Sternadori, Miglena (2016). You Act like a Girl: An Examination of Consumer Perceptions of Femvertising. Quarterly Review of Business Disciplines, 3(2), 117-128.

Bacqué, Marie-Hélène y Biewener, Carole (2016). El empoderamiento. Una acción progresiva que ha revolucionado la política y la sociedad. Barcelona: Gedisa.

Becker-Herby, Elisa (2016). The Rise of Femvertising: Authentically Reaching Female Consumers. Tesis doctoral. School of Journalism \& Mass Communication. Minneapolis: University of Minnesota Twin Cities.

Berger, John (1972). Ways of Seeing. London: Penguin.

Bernabé, Daniel (2018). La trampa de la diversidad. Cómo el neoliberalismo fragmentó la identidad de la clase trabajadora. Madrid: Akal.

Brandt, Allan (2007). The Cigarette Century: The Rise, Fall, and Deadly Persistence of the Product That Defined America. New York: Basic Books.

Carosio, Alba (2008). El género del consumo en la sociedad de consumo. La Ventana, 27, 130-169. 
De León, Magdalena (1997). Poder y empoderamiento de las mujeres. Bogotá: Tercer mundo.

Douglas, Susan (2010). The Rise of Enlightened Sexism: How Pop Culture Took Us from Girls Power to Girls Gone Wild. New York: St. Martin's Griffin.

Dowsett, Julie E. (2014). Feminism for Sale: Commodity Feminism, Femininity, and Subjectivity. Tesis doctoral. The Faculty of Graduate Studies. Ontario: York University.

Drake, Victoria E. (2017). The Impact of Female Empowerment in Advertising (Femvertising). Journal of Research in Marketing, 7(3), 593-599. doi:10.17722/jorm.v7i3.199.

Faludi, Susan (1991). Backlash: The Underclared War Against American Women. New York: Broadway Books.

Feenstra, Ramón (2013). La monitorización de la publicidad en la era digital: un reto para la ética. Cuadernos.info, 32, 47-58. doi:10.7764/cdi.32.477.

Fernández, Lola (2017). El feminismo como producto mediático. Investigaciones feministas, 8(2), 457-474. doi: 10.5209/INFE.54975.

Ferriss, Suzanne y Young, Mallory (2008). Chick flicks. Contemporary women at the movies. New York / London: Routledge.

Fraser, Nancy (1997). Justice Interruptus. Critical reflections on the 'postsocialist' condition. London: Routledge.

Fraser, Nancy (2015). Las fortunas del feminismo. Madrid: Traficantes de Sueños.

Fraser, Nancy (2018). Prefacio. Un feminismo del $99 \%$. Madrid: Lengua de Trapo.

Friedmann, John (1992). Empowerment. The Politics of Alternative Development. Oxford: Blackwell.

Gay, Roxane (2018). Hambre. Memorias de mi cuerpo. Madrid: Capitán Swing.

Gill, Rosalind (2007). Gender and the Media. Cambridge: Polity. Gill, Rosalind (2008a). Commodity Feminism. The International Encyclopedia of Communication. doi:10.1111/b.9781405131995.2008.x. 
Gill, Rosalind (2008b). Empowerment/Sexism: Figuring Female Sexual Agency in Contemporary Advertising. Feminism \& Psychology, 18(1), 35-6o. doi: 10.1177/0959353507084950.

Gladwell, Malcolm (6 de julio, 1998). The spin myth. New Yorker Magazine, 66-72.

Goldman, Robert, Heath, Deborah y Smith, Sharon L. (1991). Commodity Feminism. Critical Studies in Media Communication, 8(3), 333-351. doi: 10.1080/15295039109366801.

Hernández-Ruiz, Alejandra, Martín, Marta y Beléndez, Marina (2012). La representación de la mujer en publicidad: (des) igualdad cuantitativa y cualitativa en la creatividad española. Estudios sobre el Mensaje Periodístico, 18, 521-530. doi: 10.5209/revESMP.2012.v18.40931.

Jalakas, Lisa (2017). The Ambivalence of \#Femvertising: Exploring the Meeting between Feminism and Advertising through the Audience Lens. En Askanius, Tina (Ed.). Excellent MSc Dissertations 2016. Lund: Lund University.

Jiménez, María Luisa (2012). De antorcha de libertad a estigma: resignificaciones del consumo femenino de tabaco. Clepsydra, 11, 79-101.

Knoll, Silke, Eisend, Martin y Steinhagen, Josefine (2011). Gender Roles in Advertising: Measuring and Comparing Gender Stereotyping on Public and Private TV Channels in Germany. International Journal of Advertising, 30(5), 867-888. doi: 10.2501/IJA30-5-867-888.

Lazar, Michelle (2006). Discover the Power of Femininity! Analyzing Global «Power Femininity» in local Advertising. Feminist Media Studies, 6(4), 505-517. doi: 10.1080/14680770600990002.

Lynn, Susan, Hardin, Mary y Walsdorf, Kristie (2004). Selling (out) the Sporting Woman: Advertising Images in Four Athletic Magazines. Journal of Sport Management, 18(4), 335-349. doi: 10.1123/jsm.18.4.335. 
Marcus, Katherine B. (2016). Why Can't Run 'Like a Girl' Also Mean Win the Race? Commodity Feminism and Participatory Branding as Forms of Self-Therapy in the Neoliberal Advertising Space. Senior Thesis. Claremont: Scripps College.

McArthur, Leslie y Resko, Beth (1975). The Portrayal of Men and Women in American Television Commercials. The Journal of Social Psychology, 97(2), 209-220. doi: 10.1080/00224545.1975.9923340.

McRobbie, Angela (2007). Top Girls? Cultural Studies, 21(4-5), 718-737. doi: 10.1080/09502380701279044.

McRobbie, Angela (2009). The Aftermath of Feminism: Gender, Culture and Social Change. London: SAGE.

Medeiros, Maria Clara, Bulhões, Juliana y Dantas, Alberto (2015). O Femvertising em Evidência: Estudo de Caso \#Likeagirl. XXXVIII Congresso Brasileiro de Ciências da Comunicação (1-15). São Paulo: Universidade Federal do Rio de Janeiro.

Menéndez, María Isabel (2015). Alianzas conceptuales entre patriarcado y postfeminismo: a propósito del capital erótico. Clepsydra, 13, 45-64.

Menéndez, María Isabel (2017). Entre neomachismo y retrosexismo: antifeminismo en industrias culturales. Prisma Social, 2, 1-30.

Mulvey, Laura (1975). Visual Pleasure and Narrative Cinema. Screen, 16(3), 6-18.

Munford, Rebecca y Waters, Melanie (2013). Feminism and Popular Culture: Investigating the Postfeminist Mystique. London: I. B. Tauris.

Navarro, Marián y Martín, Marta (2011). El sexismo publicitario: delimitación de conceptos e indicadores de género. Estudio empírico de la producción científica. Pensar la Publicidad, 5(1), 5173. doi: 10.5209/revPEPU.2011.v5.n1.3692.

Orbach, Susie (1978). Fat is a Feminist Issue. London: Paddington Press. Porroche-Escudero, Ana (2017). Análisis crítico de las campañas de prevención del cáncer de mama. En Porroche-Escudero, Ana, Coll-Planas, Gerard y Riba, Caterina (Eds.). Cicatrices (in)visibles. 
Perspectivas feministas sobre el cáncer de mama (57-69). Barcelona: Bellaterra.

Projansky, Sarah (2001). Watching Rape. Film and Television in Postfeminist Culture. New York/London: New York University Press.

Read, Jason (2009). A genealogy of homo-economicus: Neoliberalism and the production of subjectivity. Foucault Studies, 6, 25-36. doi: $10.22439 /$ fs.voio. 2465 .

Rincón, Ana (1997). ¿De qué habla Begira cuando habla de sexismo en la publicidad? Vitoria-Gasteiz: Emakunde-Instituto Vasco de la Mujer.

Rodríguez, María Pilar y Gutiérrez, Mirén (2017). Femvertising: Female Empowering Strategies in Recent Spanish Commercials. Investigaciones feministas, 8(2), 337-351. doi: 10.5209/INFE.54867.

Rowe, Kathleen (2005). Scream, la cultura popular y el feminismo de la tercera ola: «Yo no soy mi madre». Lectora, 11, 43-73.

Rowlands, Jo (1997). Questioning Empowerment: Working with Women in Honduras. Oxford: Oxfam.

Royo-Vela, Marcelo, Küster-Boluda, Inés y Vila-López, Natalia (2005). Roles de género y sexismo en la publicidad de las revistas españolas: un análisis de las tres últimas décadas del siglo XX. Comunicación y Sociedad, XVIII(1), 113-152.

Sánchez, Cande (2014). Retórica nutritiva para marcas camaleónicas. En León, José Carlos (Coord.). Change Marketers: La empresa como agente de cambio (87-112). Madrid: El Viso Media.

Sugarman, Jeff (2015). Neoliberalism and Psychological Ethics. Journal of Theoretical and Philosophical Psychology, 35(2), 103-116. doi: $10.1037 /$ aoo38960.

Valcárcel, Amelia (200o). La memoria colectiva y los retos del feminismo. En Valcárcel, Amelia, Renau, Dolors y Romero, Rosalía (Eds.). Los desafíos del feminismo ante el siglo XXI (19-54). Sevilla: Instituto Andaluz de la Mujer. 
Valdés, Isabel (2018). Violadas o muertas. Un alegato contra todas las «manadas» (y sus cómplices). Barcelona: Península breve.

Wolf, Naomi (1990). The Beauty Myth: How Images of Beauty Are Used Against Women. London: Chatto \& Windus.

Zeisler, Andi (21 de julio, 2014). Worst Sales Pitch Ever: The Ad Industry's Shameless History of Using Feminism to Sell Products. Salon. Recuperado de: goo.gl/9icDdq. [Consultado el 10 marzo de 2018]. 
38 RECERCA · DOI: http://dx.doi.org/10.6035/Recerca.2019.24.2.2 - ISSN: 1130-6149-pp. 15-38 